\title{
Preliminary results from the use of entrograms to describe transport in fractured media
}

\section{Risultati preliminari dell'uso di entrogrammi per la valutazione del trasporto in mezzi fratturati}

\author{
Daniele Pedretti, Marco Bianchi
}

\begin{abstract}
Riassunto: Gli acquiferi fratturati sono sistemi eterogenei in cui l'acqua scorre principalmente attraverso le fratture. Le dinamiche di flusso, e quindi trasporto di sostanza disciolte, sono controllate dalla distribuzione topologica e dalle proprietà idrauliche della rete di fratture (fra cui l'apertura, la conducibilità idraulica $K$ e la porosità ). Queste proprietà topologiche ed idrodinamiche sono tipicamente poco caratterizzate in applicazioni di campo, generando incertezza nelle previsioni di flusso e trasporto di flusso. Questo articolo analizza la possibile applicazione del concetto di entropia geologica, ed in particolare l'entrogramma, come un approccio per descrivere, e potenzialmente prevedere, flusso e trasporto in mezzi fratturati. Nei mezzi porosi, l'entrogramma è già stato dimostrato come un approccio effettivo per rappresentare la persistenza spaziale e la connettività degli elementi con maggiore $K$, permettendo quindi previsioni di trasporto di soluti quando correlazioni adeguate sono state trovate. Sulla base del parallelismo fra elementi a maggiore $K$ nei mezzi porosi e fratture trasmissive in mezzi fratturati, sono stati eseguite delle prove per studiare un sistema idealizzato bidimensionale con una distribuzione regolare di due famiglie di fratture, una con
\end{abstract}

Keywords: heterogeneity, solute transport, uncertainty, discrete fracture networks, modelling, geological entropy.

Parole chiave: eterogeneità, trasporto di solute, incertezza, discrete fracture networks, modellazione, entropia geologica.

\section{Daniele PEDRETTI 熟-}

Dipartimento di Scienze della terra "A. Desio"

Università degli Studi di Milano, 20133 Milano, Italia.

daniele.pedretti@unimi.it

\section{Marco BIANCHI}

British Geological Survey (BGS)

Keyworth Nottingham, NG12 5GG, United Kingdom.

marcob@bgs.ac.uk

Ricevuto/Received: 21 October 2019-Accettato/Accepted: 02 December 2019 Pubblicato online/Published online: 20 December 2019

This is an open access article under the CC BY-NC-ND license:

http://creativecommons.org/licenses/by-nc-nd/4.0/

(C) Associazione Acque Sotterranee 2019 una distribuzione spaziale più persistente dell'altra. Un modello multifase basato su modellazione discrete fracture network (DFN) è stato usato per simulare un test con traccianti, in cui una specie conservativa viene rimossa da una seconda specie immiscibile iniettata da un pozzo. Le analisi delle curve di arrivo (BTCs) della saturazione relativa di ogni fase presso un altro pozzo sono servite per studiare la relazione fra indicatori basati su entrogramma e la forma delle BTCs. I risultati iniziali sono promettenti per lo sviluppo di una valutazione più rigorosa della connessione fra diversi indicatori, che richiede principalmente le simulazioni di sistemi più realistici di fratture, fra cui sistemi multidimensionali.

Abstract: Fractured media are heterogeneous systems in which water flows primarily across rock fractures. Flow dynamics and transport of dissolved substances are controlled by the topological distribution and bydraulic properties of the fracture network (including aperture, bydraulic conductivity $K$ and porosity). These topological and bydrodynamic properties are usually insufficiently characterized in field applications, generating uncertainty in the predictions of flow and solute transport. This paper explores a possible application of the concept of geological entropy, in particular the entrogram, as an approach to describe and potentially predict flow and transport in fractured media. In porous media, the entrogram was proven to be an effective approach to represent the spatial persistence and connectivity of high $K$ patterns, enabling predictions for solute transport when proper correlations are established. Given the similarities between bigh $K$ patterns in porous media and water-bearing fractures in fractured media, preliminary tests were realized to evaluate an idealized two-dimensional fractured system with regular distribution of two sets of fracture networks, one with a more persistent spatial distribution of fractures than the other. A multiphase flow model based on discrete fracture network is used to simulate a tracer test during which a conservative species displaces an immiscible one injected through a well. The analyses of the breakthrough curves (BTCS) of the relative saturation of each phase at another well allows evaluating the relationship between entrogram metrics and the shape of the BTCs. The initial results are promising and push for a more rigorous evaluation of the link among the metrics. This would require primarily the reproduction of more realistic fracture network including multidimensional systems. 


\section{Introduction}

In fractured media, the prediction of flow and solute transport is notoriously complicated by the limited knowledge of the spatial distribution and hydrodynamic properties of the water-bearing fractures (e.g. Bonnet et al. 2001; Berkowitz 2002; Chilès 2005; Dietrich 2005; Sahimi 2011). This includes the hydraulic conductivity $(K)$, the porosity $(\varphi)$, the aperture (a) and the connectivity of the fractures (e.g. Fogg 1986; Tsang and Neretnieks 1998; Maillot et al. 2016; Pedretti et al. 2016, 2019; Hyman and Jiménez-Martínez 2018). Matrix properties are also important, as they control the exchange between water-bearing fractures and the less mobile (or immobile) zones of the domain where flow is generally stagnant and dissolved solutes experience longer residence times (Pedretti et al. 2016, 2019).

Geological entropy (Bianchi and Pedretti 2017, 2018) is a new approach that combines multiple controls of flow and solute transport in heterogeneous media. Geological entropy relies on the assumption that flow and transport are correlated to the degree of spatial order in the structure of the hydrogeological properties of the aquifer. Metrics derived from the information entropy concepts (Shannon 1948) are used to quantify the degree of spatial disorder of a system. These metrics are then linked to macroscopic characteristics of flow and transport by means of empirical correlations useful for predictive purposes. So far, applications of geological entropy have targeted saturated alluvial aquifers (Bianchi and Pedretti 2017, 2018) and unsaturated flow systems (Ye et al. 2018). Bianchi and Pedretti (2018) demonstrated that the entrogram effectively describes key features of the hydrogeological system controlling transport behaviour in porous media. Examples of these features include connected high- $K$ zones, such as gravelly-sandy facies in alluvial aquifers, where solute particles tend to converge and be channeled through while migrating in the subsurface from a source.

There are multiple analogies between heterogeneous porous and fracture media for what concerns transport. For instance, water-bearing fractures control flow and transport in a way similar to well-connected high- $K$ patterns in alluvial aquifers. On the basis of this analogy, we can expect geological entropy to be effective in the analysis of solute transport also in fractured systems. In particular, the entrogram should be able to measure the spatial persistency of the fractures as it does effectively for the patterns of connected high conductivity zones in porous media, and thus be related to flow and transport dynamics.

This work presents a preliminary numerical analysis aiming to verify the validity of this hypothesis. The analysis consists of simulating conservative tracer tests in a two-dimensional fracture network with two idealized regular geometries, one with a denser distribution of fracture than the other. A multiphase flow system where two immiscible substances coexist is studied. The resulting breakthrough curves (BTCs) from the tracer tests are compared against the entrograms and used to assess any emerging correlation between them. The analysis presented in this work is the starting point for a more rigorous analysis that will take into account more complex and realistic fracture networks.

\section{Data and methods Multiphase flow simulations}

MRST-DFN, a modified version of the MATLABbased multiphase flow code MRST (MATLAB Reservoir Simulation Toolbox; Lie 2019), was used for numerical simulations. This code includes a hybrid discrete fracture network module (DFN). In its standard version, MRST considers a single porosity system, which can be a fracture, the matrix, or an effective system that scales up flow and transport in an equivalent mixed system. The DFN module adds an extra functionality to MRST being the simulation of flow and transport in a second domain overlapping the first. Mass exchanges between the two domains can occur as in a dual-permeability system. Input files for MRST-DFN are easily modifiable making the stochastic parameterisation of the system relatively simple. Furthermore, MRST-DFN is an open-source code that can resolve several other multiphaseflow- and transport-related problems.

The key parameters used for the simulations are listed in Table 1. The simulations consider a stationary flow field in $2 \mathrm{D}$ squared domain with size $L=350 \mathrm{~m}$, oriented along a Cartesian grid (x,y) (Fig. 1). The system comprises a matrix (M) and two orthogonal sets of fractures (F1, F2). Two different setups are considered. In the first setup ("field A"), the fracture spacing for both F1 and F2 is constant and equals to $\Delta \mathrm{X}=10 \mathrm{~m}$. In the second setup ("field B"), the fracture spacing for both F1 and $\mathrm{F} 2$ is constant and equals to $\Delta \mathrm{X}=2 \mathrm{~m}$. As shown in Figure 1, the result is a denser fracture network in B compared to A, with direct implication on the transport dynamics as discussed later. The fracture intrinsic permeability, $k_{F}$, is computed from the parallel plate assumption, where $k_{F}=\mathrm{a}^{2} / 12$, with $a=10^{-3} \mathrm{~m}$. The rock matrix porosity is $\varphi=0.01$ and its intrinsic permeability is $k_{M}=10^{-17} \mathrm{~m}^{2}$. The fluid density is constant and close to that of water. These specific values represent typical rock formations with limited fracturing and mean aperture and taken from the MRST examples.

In the two fields $\mathrm{A}$ and $\mathrm{B}$, a multiphase flow system with two immiscible phases $\mathrm{P} 1$ and $\mathrm{P} 2$ is simulated in both the fractures and the matrix. Initially (time $t=0$ ), P1 has a saturation $S_{P 1}=1$ uniformly distributed in the domain, while for S2 has saturation $S_{P 2}=0$. Flow boundary conditions are set to simulate a steady-state dipole, where an injection well (" + w" in Figure 1) with pumping rate $Q=1 \mathrm{~m}^{3} / \mathrm{s}$ is located in SW corner of the 2D domain and an extraction well ("-w") with pumping rate $Q=-1 \mathrm{~m}^{3} / \mathrm{s}$ is located in the opposite NE corner of the domain. The lateral boundaries are "no-flow" boundary conditions.

A tracer test is performed on each field "A" and "B" by injecting a fluid composed uniquely of $\mathrm{P} 2$ at the injection well ("+w") and extracting both P1 and P2 from the extraction well ("-w"). Keeping the injection of P1 continuous with time, P1 progressively displaces P2 from the domain. At “-w", two breakthrough curves (BTCs) are observed, one representing 
the time-dependent change in saturation for $\mathrm{P} 1\left(\mathrm{~S}_{\mathrm{P} 1} \rightarrow 0\right)$ and one representing the change in saturation for $\mathrm{P} 2\left(\mathrm{~S}_{\mathrm{P} 2} \rightarrow 1\right)$. Using a standard approach in multiphase flow modeling, the relationship between relative permeability of each phase $\left(\mathrm{k}_{\mathrm{r} 1}, \mathrm{k}_{\mathrm{r} 2}\right)$ and the corresponding normalized relative saturation $\left(\hat{\mathrm{S}}_{1}, \hat{\mathrm{S}}_{2}\right)$ is set as a linear function (i.e. a Corey power law model with unit power) such that (Lie 2019, p. 241)

$k_{r 1}=k_{1}\left(\widehat{S}_{1}\right) \quad k_{r 2}=k_{2}\left(1-\widehat{S}_{1}\right)$

where $\mathrm{k}_{1}, \mathrm{k}_{2}$ are end-point normalization constants.

Tab. 1 - Parameters used to run the MRST-DFN simulations.

Tab. 1 - Parametri utilizzati per le simulazioni con MRST-DFN.

\begin{tabular}{|l|c|c|}
\hline \multicolumn{1}{|c|}{ Parameter } & Value & Unit \\
\hline Domain size & $350 \times 350$ & $\mathrm{~m}$ \\
\hline Fracture spacing & $\begin{array}{c}\Delta \mathrm{X}=10 \text { (Field A) } \\
\Delta \mathrm{X}=2 \text { (Field B) }\end{array}$ & $\mathrm{m}$ \\
\hline Fracture intrinsic permeability & $k_{F}=\mathrm{a}^{2} / 12$ & $\mathrm{~m}^{2}$ \\
\hline Fracture aperture & $a=10^{-3}$ & $\mathrm{~m}$ \\
\hline Rock matrix porosity & $\varphi=0.01$ & - \\
\hline Rock intrinsic permeability & $k_{M}=10^{-17}$ & $\mathrm{~m}^{2}$ \\
\hline Pumping rate & $Q=1$ & $\mathrm{~m}^{3} / \mathrm{s}$ \\
\hline
\end{tabular}

(A) Fracture spacing $\Delta \mathrm{X}=10 \mathrm{~m}$

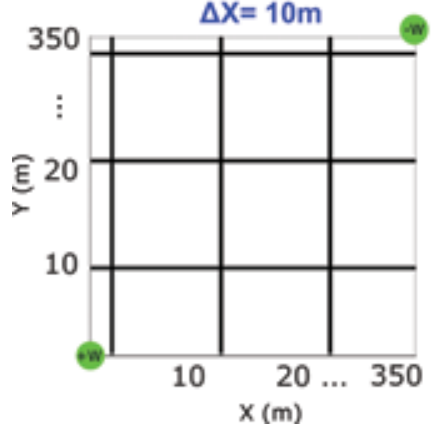

(B) Fracture spacing

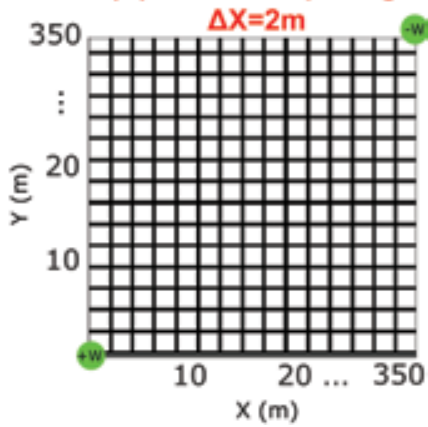

Fig. 1 - Sets of fractures and boundary conditions used for the simulations.

Fig. 1 - Distribuzione di fratture e condizioni di contorno utilizzati nelle simulazioni.

\section{Entrogram metrics}

The entrogram of fracture distributions is calculated in two steps. In the first step, the 2D lattice on which the fractures lie in the MRST model is rasterized to a binary image $(b / w)$, resulting in a "two facies" [0,1] system. The entrogram as defined in Bianchi and Pedretti (2018) is calculated from these binary images, as

$$
H_{r}(l)=\frac{1}{n_{s}(l)} \sum_{i=1}^{n_{s}} H_{R, i}^{\prime}(l)
$$

where

$$
H_{R}^{\prime}(l)=\frac{H_{L}(l)}{H_{G}} \quad H_{L}(l)=\sum_{i=1}^{n_{s}} p_{L, i}(l)\left[\ln p_{L, i}(l)\right]
$$

In (2) and (3), ns is the total number of facies (hence, $\left.n_{s}=2\right), p_{L, i}(l)$ are the local volumetric fractions (i.e., marginal probabilities of occurrence) of the categories ( 0 or 1$)$ within a subdomain whose dimensions are defined by the vector $l=l_{x} i+l_{y} j+l_{z} k$. The variable $\mathrm{H}_{\mathrm{G}}$ is the geological entropy of the entire system (here, $l=350 \mathrm{~m}$ ), which normalizes the entrogram to $\mathrm{H}_{\mathrm{R}}=1$. When applied to alluvial aquifers (Bianchi and Pedretti 2018), the entrogram measures the spatial persistency of the hydrofacies. In particular, the more persistent a facies is, the later the entrogram scales to $H_{R}=1$. The entropic scale, $H_{s}$, is a convenient metric to define the characteristic length of such spatial persistency, and it is defined as

$$
H_{s}=\int_{0}^{\infty}\left[1-H_{R}(l)\right] \mathrm{d} l
$$

A further metric of interest is the one-lag entrograms value, $H_{R}(l=1)$ (Bianchi and Pedretti 2017). Small $H_{R}(l=1)$ values corresponded to porous media that tended to have more probability to experience preferential flow and channeled transport than systems characterized by higher $H_{R}(l=1)$.

\section{Results}

Figure 2 shows the results from the application of the entrogram analysis to fields " $A$ " and " $B$ ". In the vertical axis, the figure presents the relative entropy index $\left(H_{R}\right)$, evaluated for different lag sizes $(l)$ reported in the horizontal axis. At lag $l=1$, the curves start from a value close to $H_{R}(l=1)=0.09$ for Field " $A$ " and larger value close to $H_{R}(l=1)=0.14$ for Field "B". The entrogram for Field " $A$ " tends to an asymptotic value close to $H_{R}=1$ for $l=90$, whereas the entrogram for Field "B" tends to $H_{R}=1$ for $l=25$, i.e. at much shorter scales than the one corresponding to Field "A". The entropic scales are $H_{s}=16.7$ for field " $\mathrm{A}$ " and $H_{s}=6.3$ for field "B". These results are consistent with the fact that the fracture spacing is higher in field " $A$ " than " $\mathrm{B}$ ", supporting the hypothesis that the entrogram can describe the persistency of water-bearing geological features.

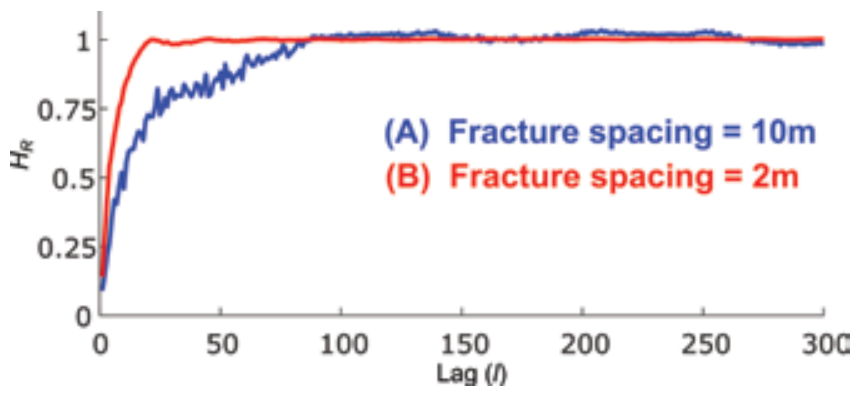

Fig. 2 - Resulting entrograms from the two fields " $A$ " and " $B$ " shown in Figure 1. The lag (l) refers to the distance between two points in each direction $(x, y, z)$ defining the subvolume to be used to calculate the local geological entropy indicators (Eqs. 2-4).

Fig. 2 - Entrogrammi risultanti dai due campi “A e "B" mostrati in Figura 1. Il lag $(l)$ rappresenta la distanza fra due punti in ogni direzione $(\mathrm{x}, \mathrm{y}, \mathrm{z})$ che definisce il sotto-volume utilizzato per il calcolo degli indicatori di entropia geologica locale (Eqs. 2-4) 
The corresponding BTCs for the two fields are reported in Figure 3. Note that time is normalized and expressed as pore volumes (PVs) to compare the two fields, which are characterized by different amounts of fractures and thus different flow velocities. The calculation of the PVs is reported in Lie (2019). The use of double-log scales emphasizes the BTC post-peak behavior or BTC "tailing”. From Figure 3, we observed that the BTC for Field "A", which is characterized by coarse fracture systems and larger entrogram scale, displays an early arrival time and slightly higher tailing than the denser-gridded field " $\mathrm{B}$ ". The overarching result is consistent with the previous links between geological entropy in porous media and shape of the BTCs emphasized by Bianchi and Pedretti (2017 2018), and in general with the expected behavior of flow and transport in heterogeneous media characterized by different lengths of characteristic patterns. It is indeed well accepted that systems with higher persistency of more permeable features and higher connectivity result in enhanced tailing than systems with lower connectivity and shorted persistency of more permeable features. (e.g. Bianchi et al. 2011; Pedretti et al. 2013, 2014; Bianchi and Zheng 2016; Pedretti and Bianchi 2018).

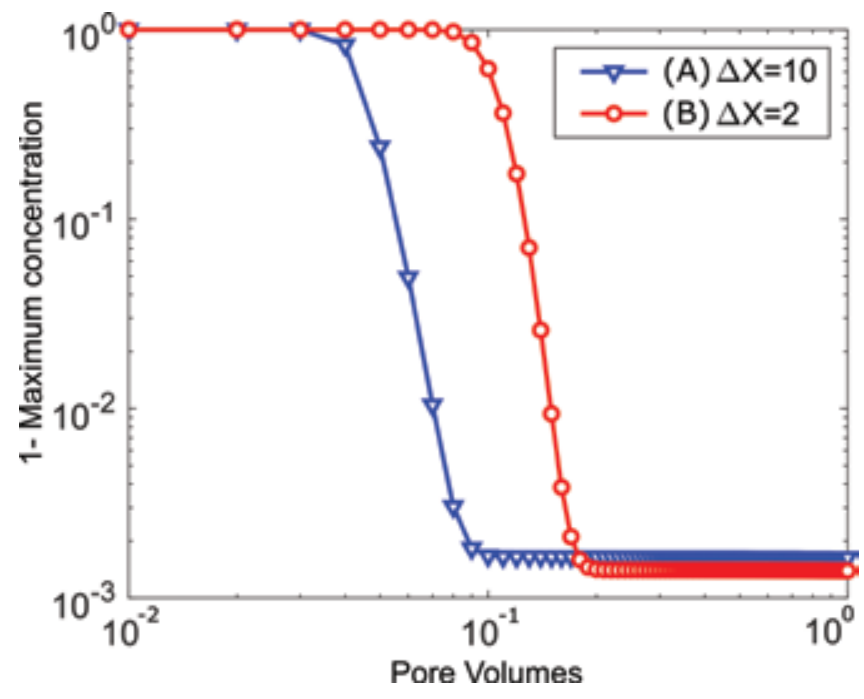

Fig. 3 - Resulting breakthrough curves of phase 2 (P2) evaluated at the extraction well ' $-w$ '. P2 enters the system through a continuous injection at well ' $+w$ ' and displaces the existing phase 1 (P1) with time. Time is here normalized and expressed as Pore Volumes.

Fig. 3 - Curve di arrivo risultanti per la fase 2 (P2) valutati nel pozzo di estrazione '-w'. P2 entra nel sistema attraverso un'iniezione continua presso il pozzo ' $+\mathrm{w}$ ' e rimuove la fase 1 (P1) esistente nel tempo. Il tempo è normalizzato ed espresso come Volumi di Poro (PVs).

The results also agree conceptually with more detailed recent studies analyzing flow and transport in fracture media using three-dimensional DFN simulations. For instance, Hyman and Jiménez-Martínez (2018) showed that the Shannon entropy of structured networks (evaluated in a different manner than through the geological entropy metrics developed here) directly influences the "mixing capacity' of the solutes in the aquifers. More chaotic structures result in greater number of heterogeneity transitions than in more ordered structures, resulting in enhanced mixing. Our results provide a similar conclusion. Field "B" has a five-times denser distribution of fractures than Field " $A$ ", resulting in higher probability of mixing of solutes in Field A than in Field B. While our simulations are based on multiphase flow of two immiscible substances and those by Hyman and JiménezMartínez (2018) reproduced transport of a substance dissolved within groundwater, the results are still comparable. Indeed, the behavior of P2 in our system is analogous to that of a conservative tracer migrating solely by advective mechanisms.

\section{Conclusion and future development}

Numerical simulations of transport in two simple fracture networks and the application of geological entropy concepts suggests that the entrogram can be a useful and parsimonious tool for describing and potentially predicting flow and transport in fractured media. This task is usually complicated by the uncertainty in model parameterisation and computational effort. Qualitatively, results from the simple systems considered in this study are consistent with more rigorous studies of fracture and porous media and provide initial insights into the next steps required to develop a more comprehensive assessment. Future developments, which may also require the derivation of other metrics linked to the concept of geological entropy, will necessarily consider more complex and realistic fracture network distributions, such as two- (2-D) and three- (3-D) dimensional irregular stochastic fracture networks. 


\section{REFERENCES}

Berkowitz B (2002) Caratterizzazione di flusso e trasporto in mezzi geologici fratturati: una revisione "Characterizing flow and transport in fractured geological media: A review". Advances in Water Resources, 25(8-12): 861-884. doi:10.1016/S0309-1708(02)00042-8.

Bianchi M, Pedretti D (2017) Entropia geologica e trasporto di soluti in mezzi porosi eterogenei "Geological entropy and solute transport in heterogeneous porous media". Water Resources Research, 53(6): 46914708. doi:10.1002/2016WR020195.

Bianchi M, Pedretti D (2018) Un approccio basato sull'entrogramma per descrivere l'eterogeneità spaziale con applicazioni di trasporto di soluti in mezzi porosi "An Entrogram-Based Approach to Describe Spatial Heterogeneity With Applications to Solute Transport in Porous Media”. Water Resources Research, 54(7): 4432-4448. doi: 10.1029/2018WR022827.

Bianchi M, Zheng C (2016) Un approccio basato su litofacies per la modellazione del trasporto di soluti non-Fickiano in un acquifero alluvionale eterogeneo "A lithofacies approach for modeling non-Fickian solute transport in a heterogeneous alluvial aquifer". Water Resources Research, 52(1): 552-565. doi:10.1002/2015WR018186.

Bianchi M, Zheng CM, Wilson C, Tick GR, Liu G, Gorelick S (2011) Connettività spaziale in un acquifero altamente eterogeneo: da carotaggi a linee di flusso preferenziale "Spatial connectivity in a bighly heterogeneous aquifer: From cores to preferential flow paths". Water Resources Research, 47: W05524. doi:10.1029/2009WR008966.

Bonnet E, Bour O, Odling NE, Davy P, Main I, Cowie P, Berkowitz B (2001) Effetto scala nei sistemi fratturati di mezzi geologici "Scaling of fracture systems in geological media". Reviews of Geophysics, 39(3): 347-383. doi:10.1029/1999RG000074.

Chilès J-P (2005) Modellazione stocastica di mezzi naturali fratturati: una revisione "Stochastic Modeling of Natural Fractured Media: A Review." In: Leuangthong O and Deutsch CV (eds) Geostatistics Banff 2004. Springer Netherlands: Dordrecht, 285-294.

Dietrich P (ed.) (2005) Flusso e trasporto in mezzi porosi fratturati. "Flow and transport in fractured porous media". Springer: Berlin; New York.

Fogg GE (1986) Flusso di acque sotterranee e interconnettività di corpi sabbiosi in un sistema multifalda spesso. "Groundwater Flow and Sand Body Interconnectedness in a Thick, Multiple-Aquifer System”. Water Resources Research, 22(5): 679-694. doi:10.1029/ WR022i005p00679.

Hyman JD, Jiménez-Martínez J (2018) Dispersione e miscelamento in reticoli di fratture discreti tridimensionali: interazione nonlineare fra eterogeneità strutturale ed idraulica "Dispersion and Mixing in Three-Dimensional Discrete Fracture Networks: Nonlinear Interplay Between Structural and Hydraulic Heterogeneity". Water Resources Research, 54(5): 3243-3258. doi:10.1029/2018WR022585.

Lie K-A (2019) Un'introduzione al simulazione di bacini con MATLAB/GNU Octave: manuale per l'uso di MATLAB Reservoir Simulation Toolbox (MRST) "An introduction to reservoir simulation using MATLAB/GNU Octave: User guide for the MATLAB Reservoir Simulation Toolbox (MRST)". Cambridge University Press.
Maillot J, Davy P, Le Goc R, Darcel C, de Dreuzy JR (2016) Connettività, permeabilità e incanalamento in modelli a fratture discrete con distribuzioni di fratture aleatorie e definite cinematicamente "Connectivity, permeability, and channeling in randomly distributed and kinematically defined discrete fracture network models". Water Resources Research, 52(11): 8526-8545. doi:10.1002/2016WR018973.

Pedretti D, Bianchi M (2018) Riprodurre le code delle curve di arrivo: i modelli statistici sono tutti ugualmente rappresentativi e predittivi? "Reproducing tailing in breakthrough curves: Are statistical models equally representative and predictive?" Advances in Water Resources, 113: 236-248. doi:10.1016/j.advwatres.2018.01.023.

Pedretti D, Fernàndez-Garcia D, Bolster D, Sanchez-Vila X (2013) Sulla formazione delle code delle curve di arrivo durante test di tracciamento con flusso convergente in acquiferi eterogenei tridimensionali "On the formation of breakthrough curves tailing during convergent flow tracer tests in three-dimensional heterogeneous aquifers". Water Resources Research, 49(7): 4157-4173. doi:10.1002/wrcr.20330.

Pedretti D, Fernàndez-Garcia D, Sanchez-Vila X, Bolster D, Benson DA (2014) Coefficienti di capacità di trasferimento di massa apparenti e direzionali in acquiferi eterogenei tridimensionali con flusso convergente radiale. "Apparent directional mass-transfer capacity coeffcients in three-dimensional anisotropic heterogeneous aquifers under radial convergent transport". Water Resources Research, 50(2): 1205-1224. doi:10.1002/2013WR014578.

Pedretti D, Luoma S, Ruskeeniemi T, Backman B. (2019) Un approccio geologico per mappare il rischio di arsenico in acquiferi cristallini: analisi della regione di Tampere, Finlandia "A geologicallybased approach to map arsenic risk in crystalline aquifers: Analysis of the Tampere region, Finland". Geoscience Frontiers. doi:10.1016/j. gsf.2018.12.004.

Pedretti D, Russian A, Sanchez-Vila X, Dentz M (2016) Dipendenza spaziale delle proprietà idrauliche di un aquifero fratturato stimata attraverso funzioni di trasferimento "Scale dependence of the hydraulic properties of a fractured aquifer estimated using transfer functions". Water Resources Research, 52(7): 5008-5024. doi:10.1002/2016WR018660.

Sahimi M (2011) Flusso e trasporto in mezzi porosi e sistemi rocciosi fratturati. "Flow and Transport in Porous Media and Fractured Rock". Wiley-VCH Verlag GmbH \& Co. KGaA: Weinheim, Germany.

Shannon CE (1948). Un teoria matematica della comunicazione "A mathematical theory of communication". Bell system technical journal, 27(3): 379-423.

Tsang CF, Neretnieks I (1998) Incanalamento del flusso in siste$\mathrm{mi}$ rocciosi eterogenei fratturati "Flow channeling in heterogeneous fractured rocks". Reviews of Geophysics, 36(2): 275-298. doi:10.1029/97RG03319.

Ye Z, Jiang Q, Yao C, Liu Y, Cheng A, Huang S, Liu Y. (2018) Ineguaglianza varazionale parabolica per flusso di acqua a saturazione variabile in reti di fratture eterogenee "The Parabolic Variational Inequalities for Variably Saturated Water Flow in Heterogeneous Fracture Networks". Geofluids, Article ID 9062569, pp. 1-16. doi: $10.1155 / 2018 / 9062569$ 